\title{
Evaluation of industrial tomato genotypes in open-field production
}

\section{Anna Rita TÓTH, Tímea RUBÓCZKI, Mária TAKÁCSNÉ HÁJOS}

Faculty of Agricultural and Food Sciences and Environmental Management, Institute of Horticultural Science, University of Debrecen, H-4032 Debrecen, 138 Böszörményi St., Hungary

*Corresponding author: toth.anna.rita@agr.unideb.hu

Manuscript received August 02, 2019; revised August 31, 2019; Accepted September 12, 2019

Abstract. Recently, industrial tomato production in Hungary shows an increasing tendency after a weak processing period. However, to maintain the cultivation profitable, the use of proper technology and genotype is indispensable.

In the experiment, five hybrids and one variety were evaluated in a plot experiment design on open field. The main objective was to evaluate the fruit quality of different genotypes and to determine the suitability for mechanical harvest.

According to the results, Heinz $1015 F_{1}$ and Heinz $9478 F_{1}$ had the best fruit quality for industrial processing.

Nowadays, the use of hybrids with good adaptability and resistance properties is important for a profitable production. evaluation

Keywords: economic value, quality examination, sensory, profitable production,

\section{Introduction}

At present, tomato has one of the largest producing areas worldwide, and it is indispensable not only for fresh market but for the industry as well [3]. It is an especially fast-developing sector: in a little more than a decade, it has grown by $49 \%$ [1]. According to the statistics, the total growing area is more than 4.8 million hectares worldwide, of which a little more than 182 million tons were harvested [2]. Tomato is important not only worldwide but in Hungary as well.

In Hungary, the total production area of industrial tomato was 2,200 hectares in 2017, of which nearly 185 thousand tons were harvested [4]. All produced tomato is processed in Hungarian factories [5]. Univer, which is the principal 
tomato-processing company in Hungary, was the $37^{\text {th }}$ in the world ranking in 2018 [7].

Currently, the main problem is the low takeover price and the rise of production prices. The minimum production value is 70 tons per hectare. Thereby, to make production profitable, the yield has to reach 100 tons per hectare [6].

\section{Materials and methods}

The experiment was carried out at the University of Debrecen, Farm and Regional Research Institute, Botanical and Exhibition Garden, on an open field in 2017. The soil type was lowland chernozem. After the harvest, different quality parameters were examined on the berries.

\section{Experiment progress}

In order to have representative results, the following six genotypes were evaluated: Heinz $1015 F_{1}$, Heinz $9478 F_{1}$, NUN $254 F_{1}$, Prestomech $F_{1}$, Rustico $F_{1}$, and Kecskeméti 407. The planting date was 5 May 2017. The parcel size was $80 \times 45 \mathrm{~cm}$ with 21-30 plants. Harvesting was carried out on 30 August 2017.

\section{Conducted measurements}

The measurements were conducted immediately after the harvest. The following physical parameters were evaluated: fruit shape index (length/ diameter), weight of berries ( $\mathrm{g} /$ piece), yield of plants ( $\mathrm{g} / \mathrm{plant}$ ), water-soluble dry matter content (Brix\%) with hand refractometer (PAL-BX/RI), and firmness of the berries $\left(\mathrm{g} \mathrm{cm}^{-2}\right)$ with Magness-Taylor pressure tester. Furthermore, skin thickness was calculated - measuring the force needed to tear the skin $\left(\mathrm{kg}^{-1}\right)$ with TA.XT Plus Texture Analyzer. The sensory evaluation was carried out for 12 properties, which were rated from one to five, by 15 persons.

\section{Results and discussions}

The berries were evaluated for different quality parameters right after the harvest. The main objective was to select the proper genotypes for the Hungarian growing conditions. 


\section{Fruit shape index}

The shape of the berries during mechanical harvest is of utmost importance. The fruit shape index is the length of the berry divided by its diameter. If the result equals one, the berry is spherical. When the result is less than one, the berry is flat, and when the result is more than one the berry is oval. For mechanical harvest, the best shape is oval, with a fruit shape index between 1.0 and 2.0.

The fruit shape index of the evaluated genotypes is shown in Figure 1 and the evaluated berries in Figure 2.

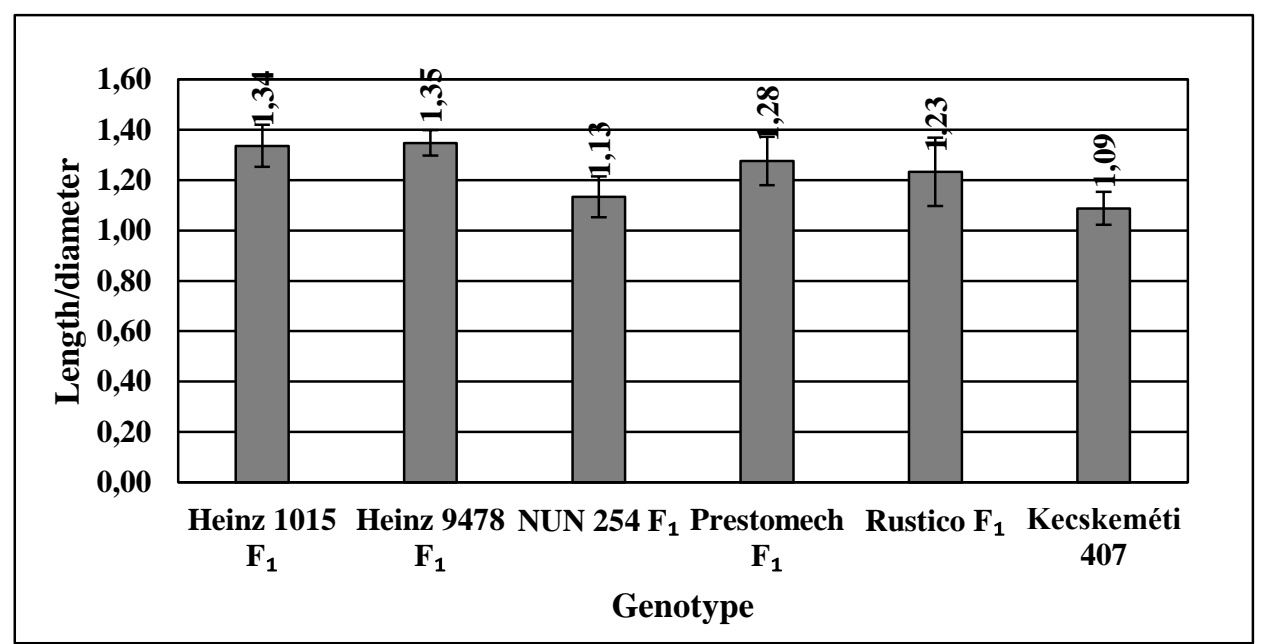

Figure 1. Fruit shape index of the evaluated genotypes

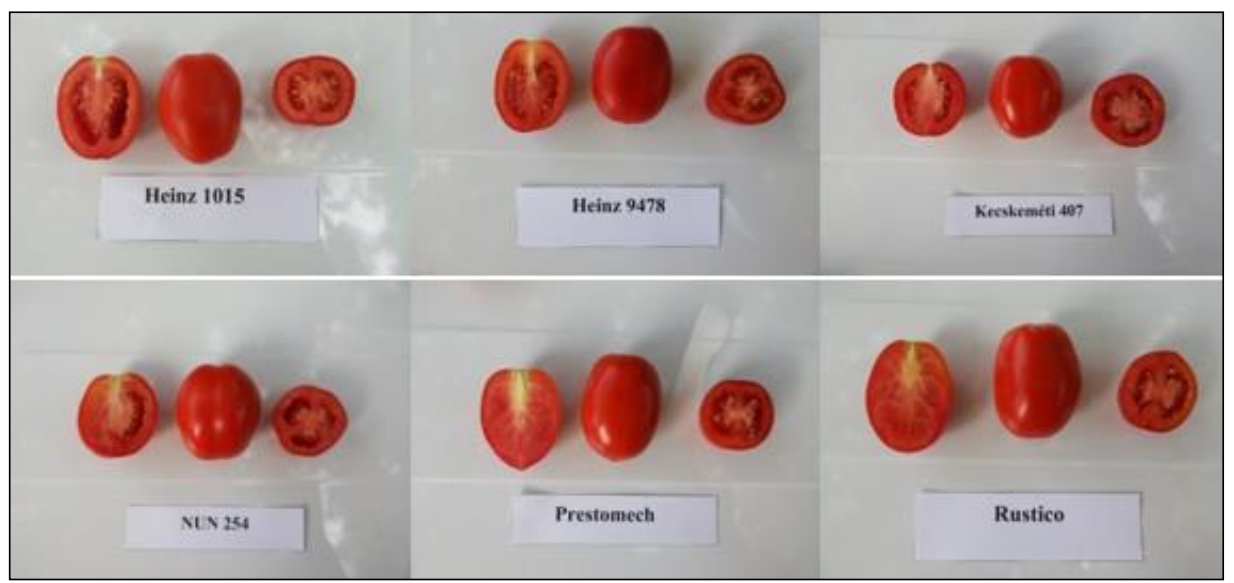

Figure 2. Fruit shape index of the evaluated genotypes 
Heinz $1015 F_{1}$ and Heinz $9478 F_{1}$ had the highest values, the average of the two genotypes showing no statistical difference. $N U N 254 F_{l}$ and Kecskeméti 407 had the lowest values (1.13 and 1.09). Kecskeméti 407, the only examined openpollinated variety, can also meet the requirements with its barely oval shape.

According to the results, all the examined genotypes are suitable for the industry, with a fruit shape index between 1.0 and 2.0.

Weight of the berries and yield per plant

Uniform berry weight plays a major role in harvesting: the key of successful mechanical harvesting is the similar shape and size of the berries, which is highly influenced by the weight of the berries. The other important parameter, which should be examined together with berry weight, is the yield of the plants.

Presently, the main goal is to reach $100 \mathrm{t} \mathrm{ha}^{-1}$ yield to make the production profitable. To reach this objective, it is important to use proper genotypes, which have not only unified berry weight but proper yield as well.

In the last few years, the number of plants per hectare has decreased from 50 thousand to 35-38 thousand according to farmers' reports. This increases the need to choose genotypes with higher yield per plant.

The evaluated genotypes have different values, which are presented in Table 1.

Table 1. Marketable yield of the evaluated genotypes

\begin{tabular}{l|cc}
\hline & $\begin{array}{c}\text { Berry weight } \\
(\mathbf{g} \text { per piece })\end{array}$ & $\begin{array}{c}\text { Marketable yield per } \\
\text { plant }(\mathbf{g} \text { per plant })\end{array}$ \\
\hline Heinz $\mathbf{1 0 1 5} \boldsymbol{F}_{\boldsymbol{1}}$ & $56.80 \pm 8.02$ & 2,712 \\
Heinz $\mathbf{9 4 7 8} \boldsymbol{F}_{\mathbf{1}}$ & $64.08 \pm 5.94$ & 3,016 \\
NUN 254 $\boldsymbol{F}_{\mathbf{1}}$ & $68.20 \pm 5.22$ & 1,636 \\
Prestomech $\boldsymbol{F}_{\mathbf{1}}$ & $69.20 \pm 4.96$ & 1,587 \\
Rustico $\boldsymbol{F}_{\mathbf{1}}$ & $62.70 \pm 4.72$ & 1,239 \\
Kecskeméti 407 & $77.70 \pm 9.35$ & 560 \\
\hline
\end{tabular}

Even though Kecskeméti 407 had the lowest marketable yield per plant due to sunburnt foliage, it yielded the highest berry weight. However, the high standard deviation shows the non-uniformity of the variety, which can influence the mechanical harvest.

Regarding to berry weight, Heinz $1015 F_{1}$ had the lowest mean, and the standard deviation was rather high $(56.80 \pm 8.02 \mathrm{~g})$. Meanwhile, the yield of the plants was especially good, the marketable yield being a little more than $2.7 \mathrm{~kg}$ per plant. 
Concerning yield per plant data, the best result belongs to Heinz $9478 F_{1}$, which produced a little more than $3 \mathrm{~kg}$ of marketable yield per plant $(3,016 \mathrm{~g})$.

\section{Water-soluble dry matter content}

One of the most important quality parameters of industrial tomato is the water-soluble dry matter content, which was evaluated after the harvest. This parameter and the proper harvesting time (before 20 August) determine the purchase price. The mentioned two parameters can alter the price both in a positive and in a negative way.

For the food industry, the required value is 5.0 Brix degree, above which the recipient raises the acceptance price. The other important value is 4.7 Brix degree: below this, the acceptance price decreases. The results of the evaluated genotypes are shown in Figure 3.

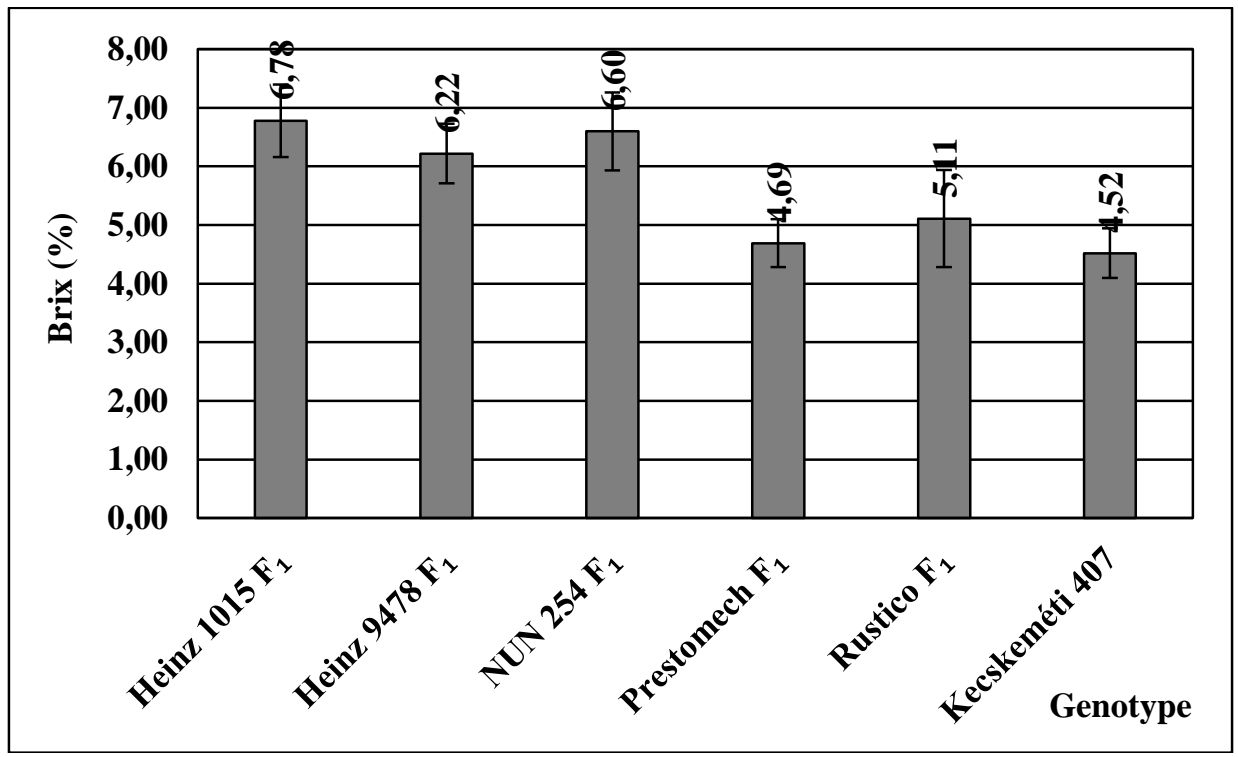

Figure 3. Water-soluble dry matter content (Brix\%) of the evaluated genotypes

According to the results, the examined genotypes can be divided into two groups. In the first group, there are three hybrids: the firmly good Heinz $1015 F_{1}$, Heinz $9478 F_{1}$, and NUN $254 F_{1}$, with high water-soluble dry matter content and higher than 6.0 Brix degree. In our growing circumstances, these hybrids were the most prosperous considering industrial production. 
The other group was composed of the other three genotypes, Prestomech $F_{1}$, Rustico $F_{1}$, and Kecskeméti 407. The Brix values of these three genotypes are close to 5.0, only the Rustico $F_{l}$ exceeding this value.

\section{Firmness and skin thickness}

Besides water-soluble dry matter content, firmness and skin thickness are two of the main quality parameters of industrial tomato. The berries have to be resistant against injuries during mechanical harvest and transport because injured berries begin to deteriorate very quickly. The results for the examination of these quality parameters are shown in Table 2.

Firmness must be at least $1,200 \mathrm{~g}$ per $\mathrm{cm}^{-2}$ to fulfill the requirements of the industry. All of the evaluated genotypes meet this value. However, there is no significant difference between the results of each hybrid.

The other important quality parameter is skin thickness, which can be measured by the force needed to tear the skin. It is at least as important from the viewpoint of damages as firmness. Skin thickness is the main quality parameter, which determines the resistance of the berries to mechanical injuries during the harvest and transport.

One of the evaluated genotypes had outstanding results: the Kecskeméti 407 needed extremely high (0.680), nearly eight times stronger force to tear the skin compared to the evaluated hybrids. The hybrids needed nearly equal force to tear the skin, but none of them reached the value of $0.100 \mathrm{~kg}$.

Table 2. Firmness and skin thickness of the evaluated genotypes

\begin{tabular}{c|cc}
\hline Genotype & $\begin{array}{c}\text { Firmness } \\
\left(\mathbf{g ~ c m}^{-2}\right)\end{array}$ & Skin thickness $\left(\boldsymbol{k g}^{-1}\right)$ \\
\hline Heinz $\mathbf{1 0 1 5} \boldsymbol{F}_{\boldsymbol{I}}$ & $1,601.9 \pm 179.45$ & $0.089 \pm 0.018$ \\
Heinz $\mathbf{9 4 7 8} \boldsymbol{F}_{\boldsymbol{I}}$ & $1,458.0 \pm 204.33$ & $0.071 \pm 0.015$ \\
NUN 254 $\boldsymbol{F}_{\boldsymbol{I}}$ & $1,333.0 \pm 183.49$ & $0.085 \pm 0.022$ \\
${\text { Prestomech } \boldsymbol{F}_{\boldsymbol{I}}}_{\text {Rustico } \boldsymbol{F}_{\boldsymbol{I}}}$ & $1,320.0 \pm 115.95$ & $0.067 \pm 0.018$ \\
Kecskeméti 407 & $1,243.0 \pm 107.61$ & $0.083 \pm 0.018$ \\
\hline
\end{tabular}




\section{Sensory evaluation}

As part of the experiment, sensory evaluation was carried out with 12 quality parameters.

Nowadays, the utilization of industrial tomato is becoming more and more widespread. In some cases, farmers can target the fresh market. In such cases, the detectable parameters are more important: costumers choose based on appearance; it is not possible to taste the products.

However, during industrial production, the quality parameters are more important because using less additives means better product quality and higher prices (additive-free and bio-products are more expensive).

According to our results, Heinz $1015 F_{1}$ and Heinz $9478 F_{1}$ had the proper quality parameters to fulfill the needs of the fresh market. Meanwhile, for industrial utilization, Heinz $9478 F_{l}$ had the best results in all but two parameters (Table 3).

Table 3. Sensory evaluation of the examined genotypes

\begin{tabular}{|c|c|c|c|c|c|c|}
\hline & $\begin{array}{c}\text { Heinz } \\
1015 F_{1}\end{array}$ & $\begin{array}{c}\text { Heinz } \\
9478 F_{1} \\
\end{array}$ & $\begin{array}{c}N U N 245 \\
F_{1} \\
\end{array}$ & $\begin{array}{c}\text { Prestomech } \\
F_{1} \\
\end{array}$ & $\begin{array}{c}\text { Rustico } \\
F_{1} \\
\end{array}$ & $\begin{array}{c}\text { Kecskeméti } \\
407\end{array}$ \\
\hline App & $40 \pm 0.52$ & $4.70 \pm 0.48$ & $3.70 \pm 0.67$ & $3.80 \pm 1.03$ & $4.00 \pm 0.67$ & $4.00 \pm 0.47$ \\
\hline Colour & $4.60 \pm 0.52$ & $4.80 \pm 0.42$ & $3.40 \pm 0.70$ & $4.30 \pm 0.48$ & $4.60 \pm 0.52$ & $4.00 \pm 0.67$ \\
\hline Firmn & $4.00 \pm 1.05$ & $4.40 \pm 0.70$ & $3.80 \pm 0.92$ & $3.70 \pm 0.67$ & $4.30 \pm 0.67$ & $4.10 \pm 1.10$ \\
\hline Sweet taste & $3.50 \pm 0.71$ & $3.60 \pm 0.84$ & $2.90 \pm 0.57$ & $3.00 \pm 0.67$ & $3.00 \pm 1.15$ & $2.80 \pm 1.32$ \\
\hline Acidity & $4.00 \pm 0.67$ & $4.10 \pm 0.74$ & $3.60 \pm 0.97$ & $3.40 \pm 0.70$ & $3.30 \pm 1.16$ & $3.30 \pm 1.25$ \\
\hline $\begin{array}{c}\text { Tomato } \\
\text { taste }\end{array}$ & $4.20 \pm 0.63$ & $4.00 \pm 0.82$ & $3.10 \pm 0.74$ & $2.90 \pm 0.57$ & $3.40 \pm 0.84$ & $2.70 \pm 1.06$ \\
\hline $\begin{array}{c}\text { Skin } \\
\text { thickness }\end{array}$ & $3.00 \pm 1.33$ & $3.40 \pm 1.17$ & $2.70 \pm 1.06$ & $2.90 \pm 1.37$ & $3.00 \pm 1.41$ & $2.80 \pm 1.03$ \\
\hline Consistency & $4.00 \pm 0.82$ & $4.50 \pm 0.71$ & $3.70 \pm 0.95$ & $3.90 \pm 1.20$ & $4.20 \pm 1.03$ & $3.90 \pm 0.74$ \\
\hline Juiciness & $3.20 \pm 1.14$ & $3.50 \pm 0.97$ & $3.50 \pm 1.08$ & $3.40 \pm 1.17$ & $3.30 \pm 1.06$ & $3.40 \pm 1.07$ \\
\hline Sour & $3.90 \pm 1.60$ & $4.00 \pm 1.63$ & $3.40 \pm 1.58$ & $3.20 \pm 1.48$ & $3.40 \pm 1.43$ & $3.00 \pm 1.63$ \\
\hline $\begin{array}{c}\text { Unpleasant } \\
\text { aftertaste }\end{array}$ & $4.70 \pm 0.48$ & $4.80 \pm 0.42$ & $3.90 \pm 1.45$ & $4.40 \pm 0.70$ & $4.10 \pm 0.74$ & $3.90 \pm 1.20$ \\
\hline $\begin{array}{c}\text { Overall } \\
\text { impression }\end{array}$ & $4.10 \pm 0.74$ & $4.40 \pm 0.52$ & $3.30 \pm 0.95$ & $3.60 \pm 0.97$ & $3.50 \pm 0.71$ & $3.10 \pm 1.29$ \\
\hline
\end{tabular}




\section{Conclusions}

Tomato has one of the largest producing areas worldwide. In the last few years, its growing area and yield have been increasing in Hungary as well.

Nowadays, the purchase price is rather low; therefore, the yield has to reach or exceed $100 \mathrm{t} \mathrm{ha}^{-1}$ for a profitable production.

In the experiment, six genotypes were evaluated on open field. The measurements verified different quality parameters: fruit shape index (length/ diameter), weight of berries ( $\mathrm{g} /$ piece), yield of plants (g/plant), water-soluble dry matter content (Brix degree), firmness of the berries $\left(\mathrm{g} \mathrm{cm}^{-2}\right)$, skin thickness, and sensory evaluation.

Finally, we can state that the Heinz $1015 F_{l}$ and Heinz $9478 F_{l}$ hybrids were the most suitable ones for industrial production in our circumstances. These hybrids stood out with rather high water-soluble dry matter content (6.22-6.78 Brix degree), optimal fruit shape index (1.34-1.35), yield of plants $(2,712-3,016$ $\mathrm{g}$ ), proper firmness $\left(1,601.9 \pm 179.45\right.$ and $\left.1,458.0 \pm 204.33 \mathrm{~g} \mathrm{~cm}^{-2}\right)$, and skin thickness $\left(0.089 \pm 0.018\right.$ and $\left.0.071 \pm 0.015 \mathrm{~kg}^{-1}\right)$.

\section{Acknowledgements}

The publication was supported by the EFOP-3.6.3-VEKOP-16-2017-00008 project. The project is co-financed by the European Union and the European Social Fund.

Publishing of this journal is supported by the Institute for Research Programmes of the Sapientia University.

\section{References}

[1] XXXX (2016), 88 million tons of fresh Tomatoes! Eurofresh Distribution 144, 42.

[2] FAO (2019), http://www.fao.org/faostat/en/\#data/QC.

[3] Gould, W. A. (2013), Tomato production, processing and technology. Third edition. Baltimore, USA: CTI Publications Inc.

[4] KSH (2019), https://www.ksh.hu/docs/hun/xstadat/xstadat_eves/i_omn004f.html.

[5] Rimóczi, I. (2018), Százezer tonna ipari paradicsom. Kertészet és szölészet 65(38), 6-9.

[6] Takácsné Hájos, M., Vas, F. (2016), Termesztési mód hatása az ipari paradicsom jövedelmezőségére. Gradus 3(2), 268-273.

[7] http://www.univer.hu/hu/aktualis/hirek/paradicsomfeldolgozok_vilagrangsora_az_univer_a _37_helyen.html. 